\title{
INFLUÊNCIA DO RELEVO E VEGETAÇÃO NA VARIAÇÃO DA TEMPERATURA E UMIDADE RELATIVA DO AR NA SERRA DO CIPÓ - MG, EM UM ESTUDO DE CURTO PRAZO
}

\author{
Ana Paula Minelli Moreira ${ }^{(a)}$, Jaqueline da Consolação Silva ${ }^{(b)}$ \\ (a) Discente de Geografia/Instituto de Geociências, UFMG, anapaulaminelli18@gmail.com \\ (b) Discente de Geografia/Instituto de Geociências, UFMG, jacquelinecsilva@ @otmail.com.br
}

Eixo: Climatologia em Diferentes Níveis Escalares: Mudanças e Variabilidades

\begin{abstract}
Resumo
$\mathrm{O}$ presente artigo analisa a influência da vegetação e topografia nas variações de temperatura e umidade relativa do ar em áreas interior ao Pq. Nacional da Serra do Cipó. Os dados foram obtidos utilizando-se resgistradores automáticos para temperaura e umidade relativa do ar instalados no interior de abrigos para coleta em campo, pelo período de 10/09/2016 à 24/09/2016. A análise considerou a relação dos dados mensurados com as características físicas do ambiente (relevo e cobertura vegetal) sob condições atmosféricas diferenciadas além da importância da vegetação fator de dissipação do calor.
\end{abstract}

Palavras chave: vegetação, topografia, microclimas, mesoclimas.

\section{Introdução}

A Serra do Cipó é de suma importância para a região onde se encontra, sendo um dos principais pontos turísticos de toda Minas Gerais. Na Serra, inserida na região metropolitana de Belo Horizonte, pode-se encontrar grande biodiversidade de beleza cênica ímpar. Vale lembrar que também tem sua importância no quesito econômico, uma vez que a região é alvo de grandes empreendimentos que visam atrair ainda mais o turismo para a região.

É importante entender qual é o papel do homem na transformação da paisagem e qual a intensidade dessa transformação. A intervenção antrópica é um dos fatores condicionantes do clima, nos quais tem na zona urbana sua maior área de impacto. A ação antropogênica pode causar alterações como a redução da vegetação, uso indevido do solo (que pode levar a sua impermeabilização), assoreamento de rios etc. Entretanto, é importante estabelecer se o homem realmente tem grande impacto na área estudada.

Quando se trata de geografia - e mais especificamente de climatologia - não se pode esquecer de analisar os processos de acordo com sua escala de ocorrência, uma vez que um fator que influência numa escala global nem sempre influencia numa escala local e regional. Entre outros autores, o papel da escala nos estudos climotológicos pode ser averiguado em Ribeiro (1993) e Monteiro (1999). 
A sociedade é constantemente influenciada pelos sistemas naturais, desde interações mais simples, como a vestimenta utilizada de acordo com a temperatura, até na escolha do melhor local para instalação de uma estação de energia eólica, por exemplo. Porém, o inverso também acontece, onde as ações antrópicas influenciam o meio natural e, por extensão, o clima. Pode-se usar a conurbação urbana como exemplo, que produz grande área urbanizada e de impermeabilização do solo, podendo gerar o fenômeno de Ilha de Calor, influenciando localmente o clima. Visto isso, é imprescindível a análise da região para entender e esclarecer melhor essa interação homem-meio.

O não entendimento dessas relações leva a conclusões equivocadas, principalmente a respeito da temperatura, cujo aumento está relacionado com um "aquecimento global da Terra" em consequência de um suposto aumento da concentração de CO2. Sabe-se que a Terra está em constante mudança e que o clima é um sistema natural aberto, dinâmico, complexo, evolutivo e que se autorregula, conforme Monteiro (1975).

Quando se trata de clima em escala global, deve-se levar em consideração os ciclos das manchas solares, as massas de ar, além de poder ser considerado o fenômeno da Oscilação Decadal do Pacífico (ODP) e, dependendo do caso, erupções vulcânicas como as dos El Chicón no México em 1982 e Monte Pinatubo nas Filipinas em 1991 que, segundo Molion (2005), lançaram grandes quantidades de aerossóis na estratosfera, aumentando o albedo planetário, resultando em uma queda da temperatura da Terra por um período de 2 a 3 anos.

Radiação, advecção de massas de ar, aquecimento da terra e da água, correntes oceânicas, altitudes e posição geográfica são fatores que funcionam como controladores de temperatura. Na radiação, por exemplo, há interferência do dia do ano, da hora do dia, da latitude, cobertura de nuvens e da superfície albedo e radiação solar absorvida (GRIMM, 2002). No que diz respeito à superfície de aquecimento, é necessário saber suas propriedades para sabermos os níveis de reflexão, absorção, albedo e constatar o que esses processos influenciam na temperatura da área.

Por outro lado, para analisar um espaço numa escala micro, é necessário delimitar e compreender os fatores que os influenciam e como estes influenciam os elementos climáticos. O relevo, por exemplo, apresenta-se como um condicionante fundamental em muitos aspectos. Sua disposição norte/sul ou leste/oeste impacta diretamente na quantidade que recebe de radiação solar que, consequentemente, influencia na ocorrência de coberturas vegetais.

[...] superfícies com orientações e inclinações diferentes recebem quantidades diferentes de radiação solar global em comparação com uma superfície horizontal, em uma mesma localidade e época do ano. A importância desse fato é que a produção de matéria vegetal 
é condicionada pela disponibilidade de energia solar. (TUBELIS e NASCIMENTO, 1984, apud TORRES e MACHADO, 2008, p. 78)

A vegetação também tem muita influência em uma pequena escala e até em médias escalas. Em regiões tropicais, a densa vegetação é responsável por grandes processos de evapotranspiração, que deixam o ar mais carregado de umidade, facilitando a ocorrência de chuvas. Elas também influenciam na temperatura máxima, uma vez que estas são moldadas de acordo com a sombra que as árvores proporcionam, do calor que absorvem e da evaporação da água que transpiram (TORRES E MACHADO, 2008).

Os solos também são considerados um dos grandes fatores do clima, no qual pode-se observar em como as cores dos mesmos influenciam na absorção e não absorção de radiação solar. As superfícies mais escuras, em geral absorvem mais calor do que as superfícies mais claras, fazendo com que a temperatura durante o dia seja mais alta. Além da cor, pode-se notar, também, que há relação entre temperatura e material do solo, já que, segundo Torres e Machado (2008), solos com materiais arenosos têm calor específico baixo e por isso apresentam maior variação de temperatura, oposto dos efeitos de materiais argilosos, que retém a umidade e por isso tendem a conservar mais o calor e o frio.

Como se pode ver, o clima é influenciado por uma série de elementos e fatores climáticos e, portanto, a partir do momento que o homem altera a paisagem, ele pode alterar os efeitos desses componentes climáticos. Numa pequena escala, se houver alteração do solo, onde é retirada toda sua cobertura vegetal, haverá mudança na capacidade de absorção e reflexão da radiação solar. Um solo exposto recebe mais radiação solar e pode ser capaz de reter e liberar mais calor, aumentando a temperatura próxima a ele.

Vale ressaltar que a área de estudo, no Parque Nacional da Serra do Cipó (figura 1), localizada na porção sul da Cadeia do Espinhaço, é uma região montanhosa e que por isso recebe diferentes níveis de radiação solar a depender da localização da vertente. O relevo influencia, também, na disponibilidade de umidade, caso das vertentes voltadas para leste que recebem ventos vindos do oceano, favorecendo a ocorrência de chuva que, por sua vez, impactam diretamente na vegetação, mais densa nessas áreas. 


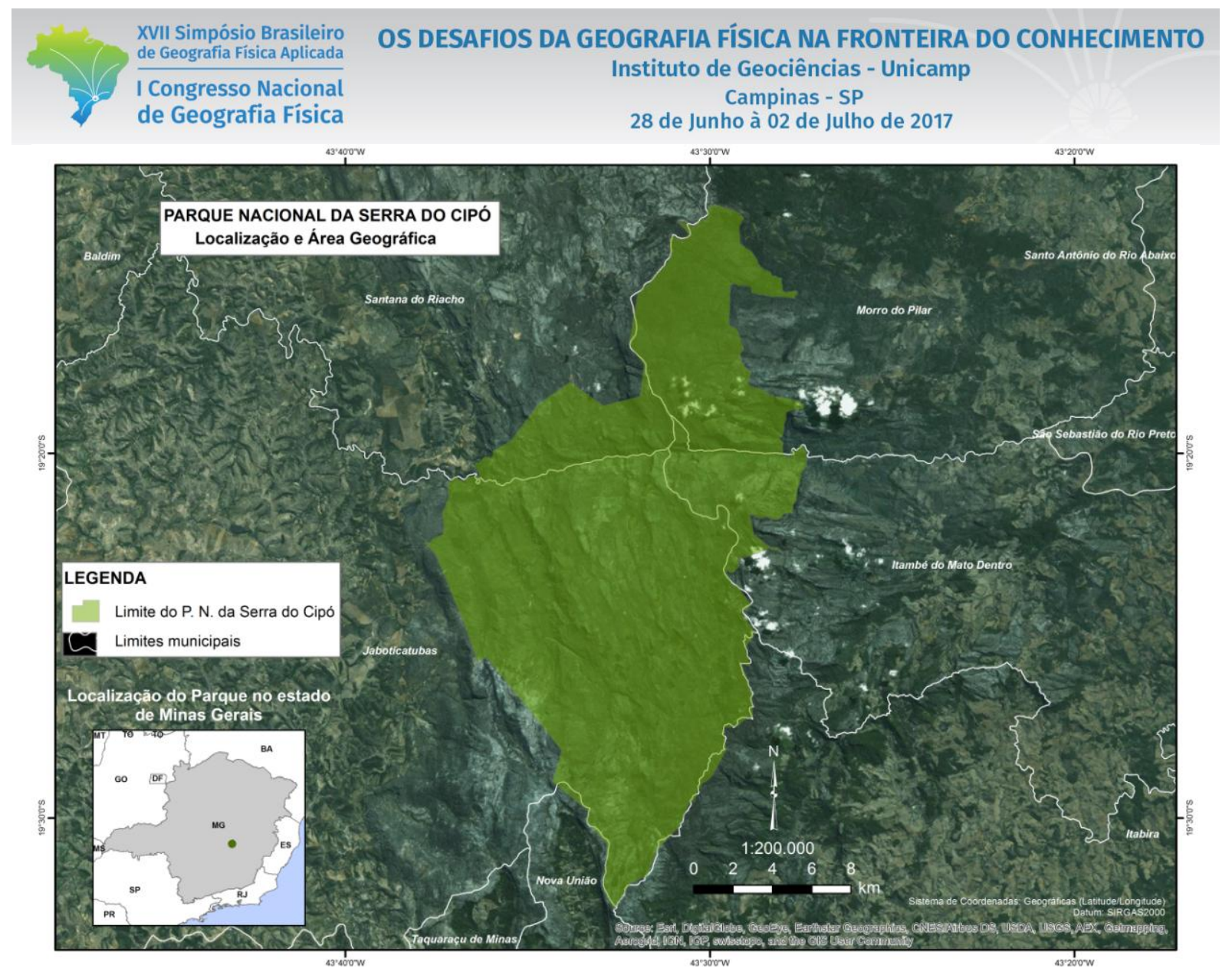

Figura 1- Localização da área de estudo. Fonte: IGTEC, 2015. Elaborado pelos autores.

Nesse sentido, o objetivo deste artigo é analisar a influência dos fatores e elementos climáticos, como o relevo, cobertura vegetal e cursos d'água nas variações de temperatura e umidade relativa do ar afim de entender a interação entre os mesmos.

\section{Procedimentos Metodológicos}

Os dados foram obtidos utilizando-se registradores automáticos para temperaura e umidade relativa do ar instalados no interior de abrigos para coleta em campo, pelo período de 10/09/2016 à 24/09/2016 no Parque Nacional da Serra do Cipó-MG. Os abrigos foram fixados em distintos pontos ao longo do dia. Também foram utilizados equipamentos para a medição das condições locais de temperatura e umidade relativa do ar:

a) Termômetro para medir a temperatura do solo em duas condições: quando exposto diretamente a radiação e quando coberto por serrapilheira e/ou protegido pela sombra da vegetação. O termômetro foi mantido em contato com o solo até que a temperatura ficasse estável. Depois disso o termômetro começa a apresentar queda nos valores da temperatura; 
XVII Simpósio Brasileiro

de Geografia Fisica Aplicada

I Congresso Nacional

de Geografia Física

\section{OS DESAFIOS DA GEOGRAFIA FÍSICA NA FRONTEIRA DO CONHECIMENTO}

Instituto de Geociências - Unicamp

Campinas - SP

28 de Junho à 02 de Julho de 2017

b) Anemômetro para medir a velocidade média dos ventos, assim como a sua orientação. O aparelho foi mantido na vertical até que os valores apresentados por ele fossem constantes;

c) Psicrômetro, usado para medir a temperatura do ar seco e úmido. $\mathrm{O}$ aparelho foi mantido em movimento rotacional constante por três minutos, para que o contato com o ar nos termômetros simulasse a temperatura nas duas condições: seca e úmida;

d) GPS, usado para obter as coordenadas geográficas e aferir a altitude de cada ponto de instalação dos abrigos;

e) Máquina fotográfica, utilizada para registrar imagens e congelar as características de cada ponto de coleta de dados e da serra de um modo geral.

Os pontos foram escolhidos com base em suas diferentes características físicas, como a altitude, disposição do relevo, tipologia da vegetação e proximidade com cursos d'água, devido às diferentes respostas do meio para os fatores postos em análise, no caso a temperatura e umidade do ar, temperatura do solo exposto e não exposto e a direção e velocidade dos ventos. A figura 2 mostra a disposição de cada ponto de coleta de dados no interior do Parque, juntamente com um perfil de elevação, mostrando a variação altimétrica entre os mesmos pontos.

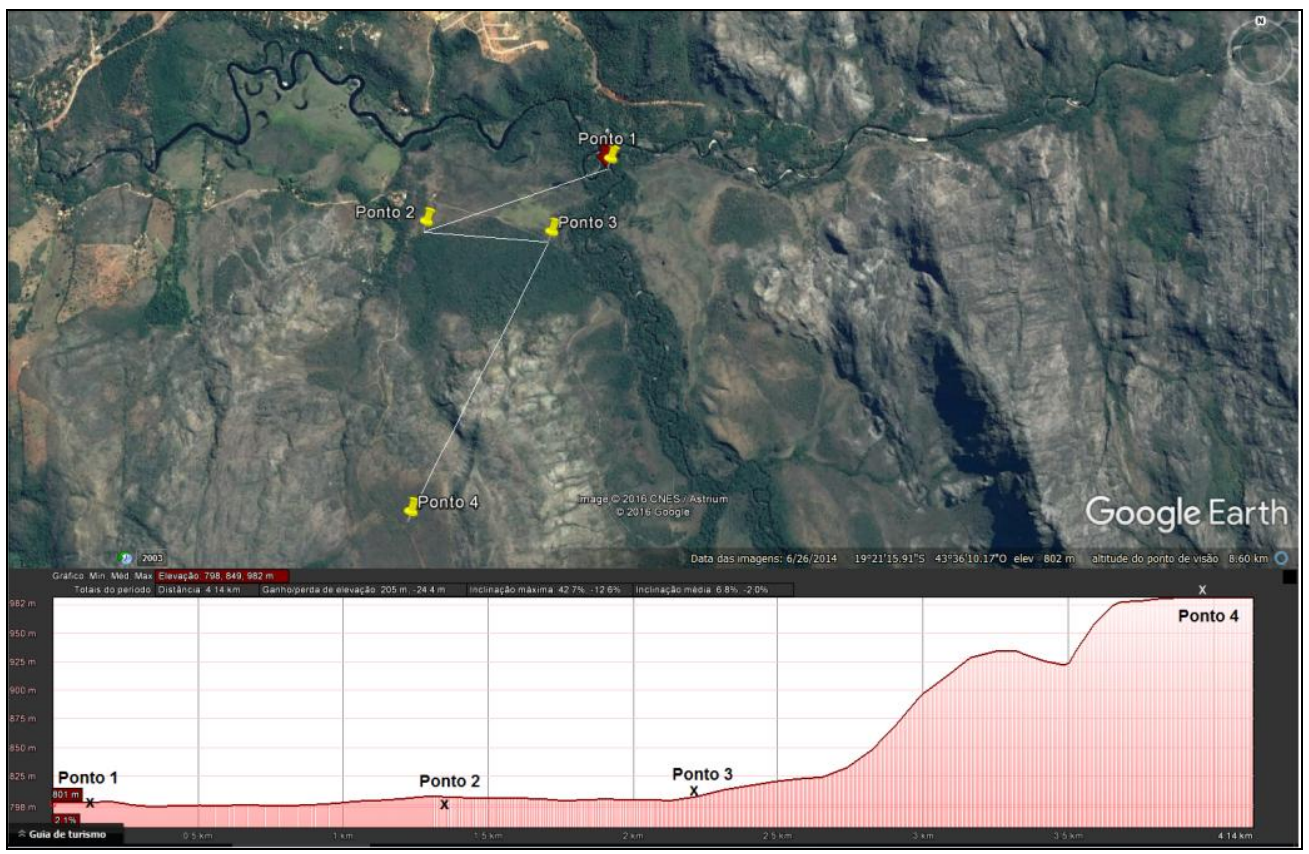

Figura 2 - Trajeto de campo realizado e pontos de coleta de dados. Fonte: Google Earth. Elaborado pelos autores. 
Após a obtenção dos dados referentes ao período de 10/09/2016 a 24/09/2016, todos eles foram organizados em forma de tabelas e gráficos, facilitando assim a visualização e compreensão dos dados coletados. Foi feita uma análise levando em consideração o ambiente de coleta de cada estação e suas características, assim como suas anomalias (valores fora da média, por exemplo), para que se pudesse fazer as comparações e considerações posteriores. Foram feitas análises pautadas na observação dos pontos e de suas características físicas, como morfologia das plantas, por exemplo, além da coleta de dados de GPS (para aferir coordenadas e altitude) e por fim, foi feito um perfil de elevação para evidenciar as formas do relevo.

\section{Resultados}

De acordo com as medições e observações em campo, foi possível a descrição detalhada dos pontos $^{1}$ quanto suas características físicas ${ }^{2}$ :

Ponto 1 - Mata Ciliar, na confluência dos ribeirões Bocaina e Mascate, coordenadas: 19²0'50,4' S, 4336’20.7' O. Ponto situado a $802 \mathrm{~m}$ de altitude e caracterizado pela presença de mata ciliar, além da baixa exposição do solo a radiação (devido à vegetação presente) que na maioria das vezes chega ao solo de forma difusa. O abrigo foi instalado às 10h42min do dia 10/09/2016.

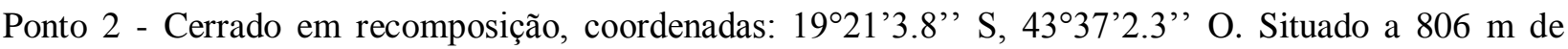
altitude, fica localizado em uma área de cerrado com vegetação em estado de recomposição devido ao grande número de queimadas ocorridas na região. O abrigo foi instalado às 11h30min do dia 10/09/2016.

Ponto 3 - Cerrado arbóreo coordenadas: 19²1'5.9' S, 43³6’33.9' O. Situado a $806 \mathrm{~m}$ de altitude, este ponto é caracterizado por uma vegetação um pouco mais densa, com árvores de porte médio, pequeno e arbustos, característica que contribui para a difusão da radiação recebida. $\mathrm{O}$ abrigo foi instalado às 15h30min do dia 10/09/2016.

Ponto 4 - Capão, coordenadas: $19^{\circ} 22^{\prime} 4.1^{\prime \prime}$ S, 43³7'3.9'’ O. Situado no ponto mais alto do trajeto, a 948 $\mathrm{m}$ de altitude, este ponto está inserido dentro do cerrado aberto, onde se observa a vegetação arbustiva e arbórea que implica numa maior receptividade da radiação solar. $\mathrm{O}$ abrigo foi instalado às 13 h00min do dia 10/09/2016.

\footnotetext{
${ }^{1}$ A nomenclatura dos pontos levou em consideração elementos que caracterizaram os mesmos, como a proximidade com o Rio Cipó, no ponto 1, a presença de vegetação queimada no ponto 2 , a maior densidade vegetacional no ponto 3, e, a proximidade com a Cachoeira do Capão no ponto 4.

2 As características relativas à vegetação correspondem ao delimitado pelo "Manual Técnico da Vegetação Brasileira", elaborado pelo Instituto Brasileiro de Geografia e Estatística (IBGE), 2012. Os pontos de coleta de dados estão inseridos no Bioma Cerrado.
} 


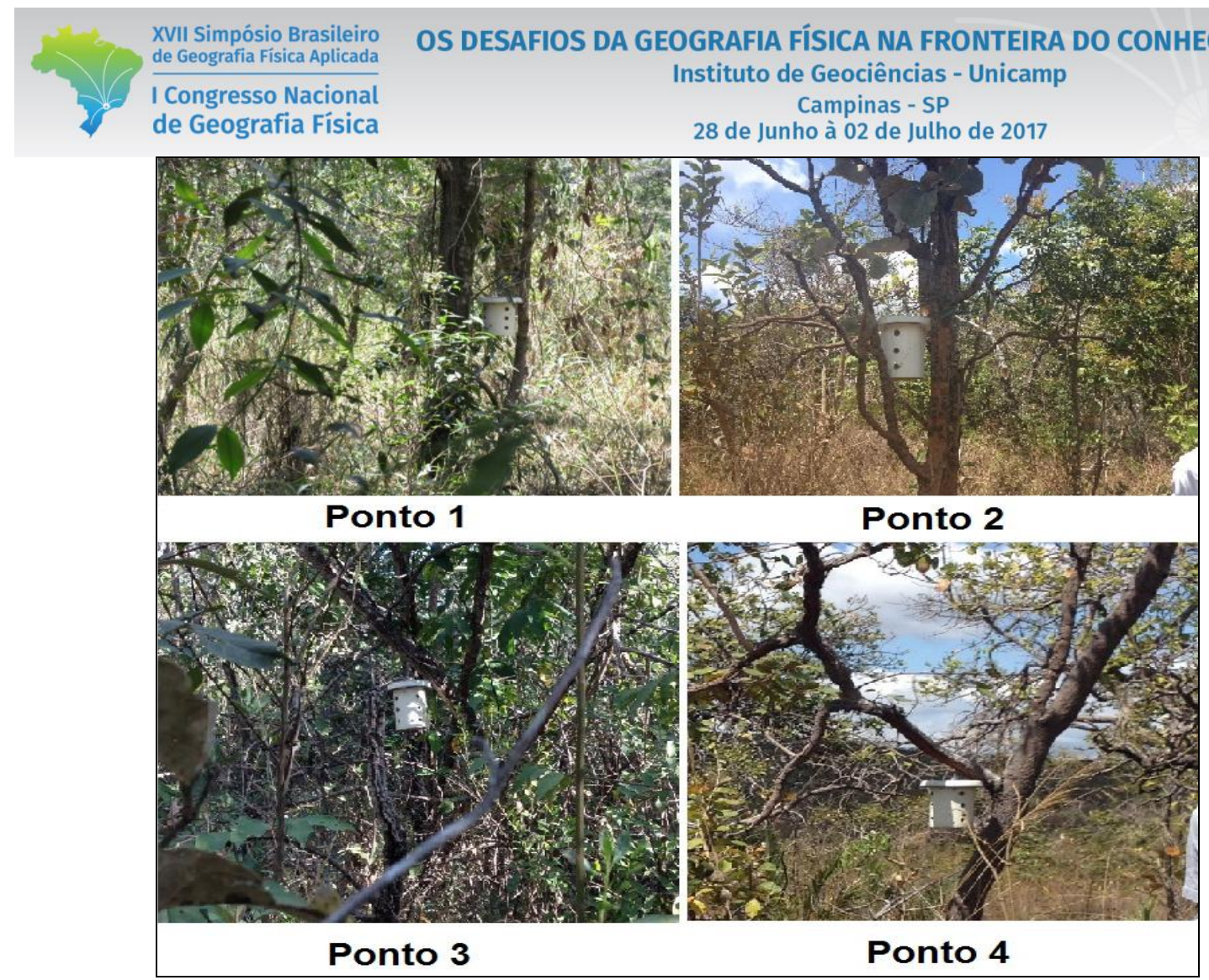

Figura 3 - Pontos de coleta de dados. Fonte: arquivo pessoal

De acordo com a observação dos dados de toda a série, desde o dia 10/09/2016 ao dia 24/09/2016, as médias de temperatura e de umidade relativa do ar nos pontos 1 - Mata Ciliar, 2 - Cerrado, 3 - Cerrado Arbóreo e 4 - Capão têm valores próximos, como pode ser visto na figura 4.

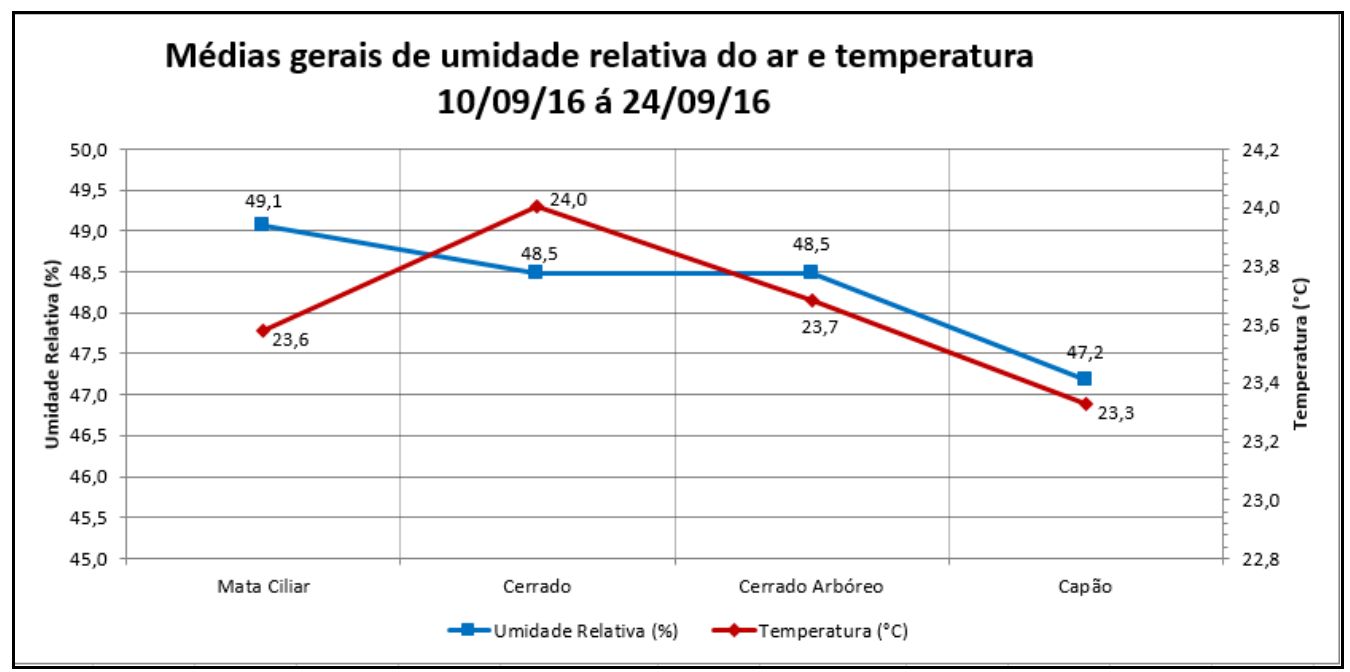

Figura 1- Médias gerais de umidade relativa do ar e temperatura. Fonte: Elaborado pelos autores. 
A proximidade dos valores pode ser explicada devido à localização dos pontos em uma mesma área geográfica, ou seja, os sistemas climáticos em escala regional que atingem um, atingem a todos. Mas ainda sim há pequena diferença entre as médias de temperatura e umidade, uma vez que cada ponto está sujeito a ação de fatores climáticos diferentes.

A título de comparação o ponto 1- Mata Ciliar e o ponto 4 - Capão apresentaram os menores valores de médias gerais de temperatura de toda a série: $23,6{ }^{\circ} \mathrm{C}$ e $23,3{ }^{\circ} \mathrm{C}$, respectivamente. Isso pode ser explicado pela vegetação, no caso da Mata Ciliar, e altitude, no caso do Capão. A vegetação funciona como uma barreira à radiação solar direta, fazendo com que a disponibilidade de energia para aquecer o ar diminua. Além disso, a camada de serrapilheira formada nos solos e a presença de raízes das árvores fazem com que o sistema tenha maior capacidade de absorção de água e, consequentemente, maior capacidade do solo de transmitir o calor que ele absorve, tornando o aquecimento do ar mais lento. Esse aumento da infiltração, juntamente com a diminuição do escoamento artificial, disponibiliza maior quantidade de água para a hidratação das plantas, que aumenta a evapotranspiração, resultando em um ar mais úmido e frio (MENDONÇA e DANNI-OLIVEIRA, 2007). Por causa desses processos, esse ponto apresenta a segunda menor média de temperatura $\left(23,6^{\circ} \mathrm{C}\right)$ e a maior média de umidade relativa do ar $(49,1 \%)$.

No caso do Capão, a altitude é o principal fator controlador de temperatura, já que está localizado a 984 metros de altitude, sendo o mais alto. Há importante relação entre temperatura, pressão atmosférica e altitude, sendo que quanto maior a altitude, menor a temperatura e menor a pressão.

A força da gravidade faz com que o ar se desloque para áreas mais baixas, fazendo com que o ar de lugares mais altos seja mais rarefeito e conseqüentemente tenha menor valor de pressão. A baixa pressão faz com que tenha menor concentração de vapor d'água e, conseqüentemente, diminuição na capacidade de reter calor, o que torna a temperatura do ar mais fria. É importante ressaltar que a altitude que se encontra esse ponto (984 m) não é exorbitante quando comparada a uma cadeia de montanha como os Andes, por exemplo, então não se pode dizer que o ar é extremamente rarefeito. Entretanto, essa diferença de altitude pode ser um fator crucial no que tange as diferenças de temperatura entre os pontos.

O Cerrado registra as temperaturas médias gerais mais altas dentre os pontos: $24{ }^{\circ} \mathrm{C}$. Analisando as características físicas da área do ponto, percebe-se a falta de vegetação, que resulta em maior exposição às intempéries e maior absorção à radiação solar direta, resultando na elevação da temperatura do ar. No Cerrado arbóreo as temperaturas médias gerais são mais baixas em relação ao Cerrado em recomposição registrando $23,7^{\circ} \mathrm{C}$. Essa diferença ocorre devido à presença das árvores que ajudam no controle dessa exposição e absorção de radiação solar direta, diminuindo os valores de temperaturas do ar. 


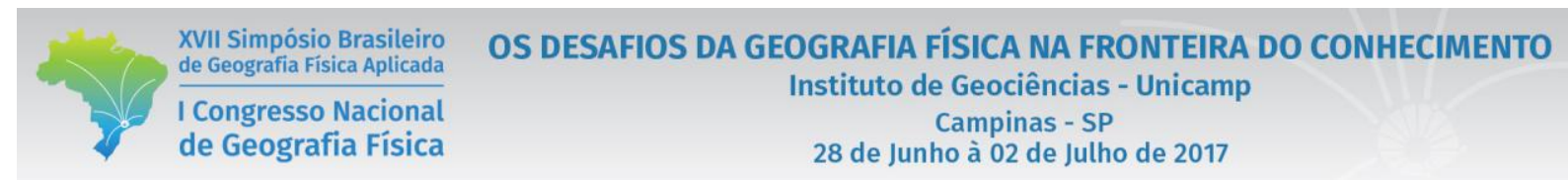

Um fator importante a ser destacado, refere-se ao relevo do ponto 1 - Mata Ciliar, o qual está localizado em um vale (802 m), no encontro do Ribeirão Bocaina com o Ribeirão Mascates formando o Rio Cipó. Desta forma, o relevo se torna um obstáculo para a chegada dos ventos (por isso, no dia 10/09/2016, foram registradas rajadas de vento de 1,5 km/h e $2 \mathrm{~km} / \mathrm{h}$ nessa área). Em contrapartida no ponto 4 - Capão, o mais alto da série $(984 \mathrm{~m})$, as rajadas de vento variaram de $4 \mathrm{~km} / \mathrm{h}$ a $19 \mathrm{~km} / \mathrm{h}$ que, devido à altitude da área, o vento consegue chegar com mais facilidade. $\mathrm{O}$ vento é também um importante condicionante à temperatura, já que este funciona como uma espécie de dispersor de massas de calor.

Comparando as médias de temperatura dos dias 15/09/2016 (dia mais quente) e 22/09/2016 (dia mais frio) com as médias de umidade dos mesmos dias, percebe-se que há grande relação entre os dois dados. Na análise dos gráficos das médias diárias, observamos que o dia 15/09/2016 foi o dia mais quente da série e o dia 22/09/2016 o dia mais frio, assim como mostra o gráfico abaixo:

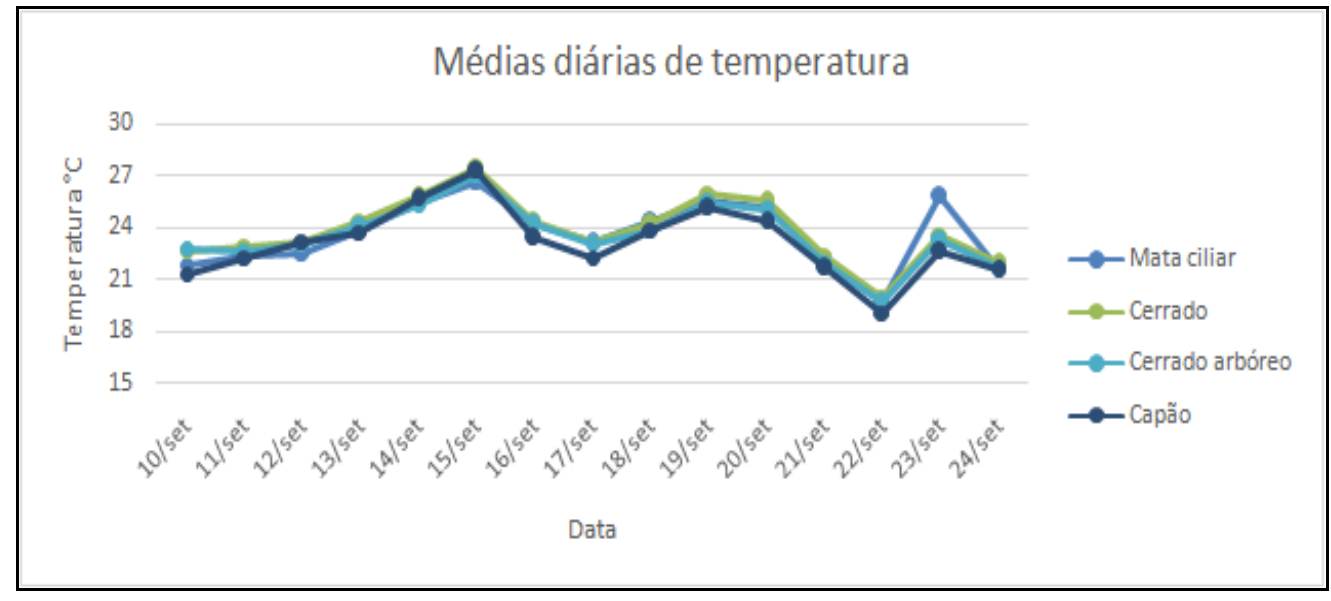

Figura 2- Médias diárias de temperatura. Fonte: Elaborado pelos autores.

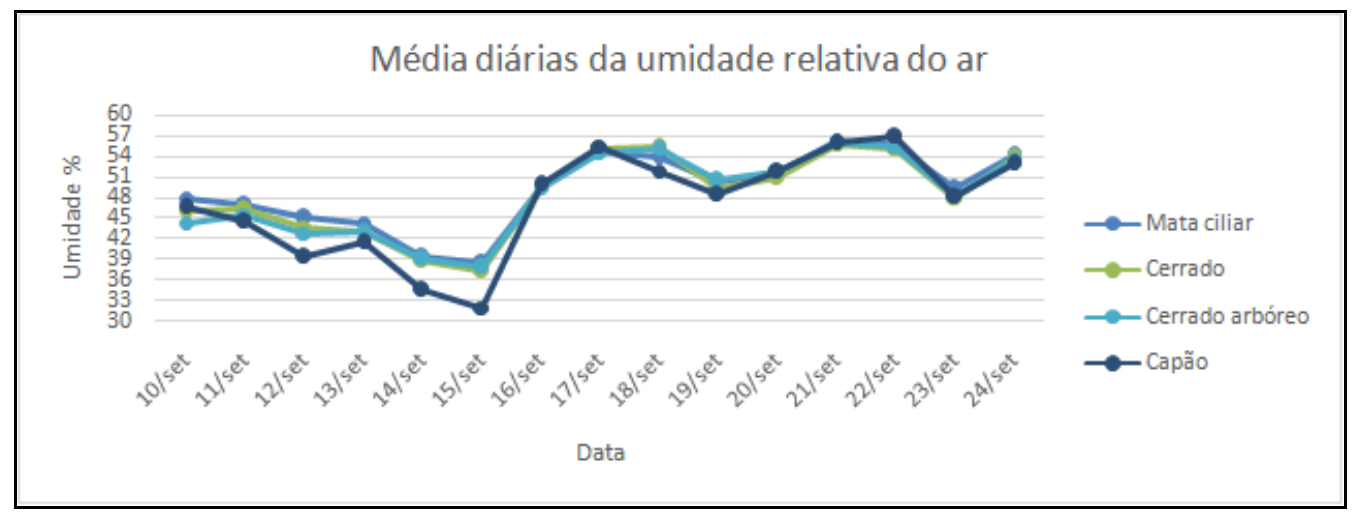

Figura 3- Médias diárias de umidade relativa do ar. Fonte: Elaborado pelos autores. 
Os valores das médias de temperatura e umidade do dia $15 / 09 / 2016$ foi $27,1^{\circ} \mathrm{C}$ e $36,3 \%$ e do dia $22 / 09 / 2016$ foi de $19,5{ }^{\circ} \mathrm{C}$ e $55,8 \%$. Nesse caso verifica-se que o dia de maior temperatura registrou também o menor valor de umidade relativa do ar, enquanto o dia de menor temperatura registrou o maior valor de umidade relativa do ar. Tais valores (temperatura e umidade relativa do ar) são inversamente proporcionais, uma vez que, quanto maior a temperatura, maior será também a disponibilidade de espaço para as moléculas de água se movimentar no sistema, devido a menor densidade do ar. Desta forma, mesmo que a quantidade de vapor d'água presente nesse ambiente com o ar quente seja igual ao de um ambiente com o ar mais frio, a umidade relativa do ar será menor, já que precisará de uma maior quantidade de vapor d'água para a saturação nesse ambiente. Na situação de menores valores de temperaturas e maior densidade do ar, as moléculas de água se agrupam, devido a maior densidade do ar e o menor espaço para as mesmas.

Analisando as temperaturas horárias dos pontos, duas situações chamaram a atenção, referente aos dados dos dias 14 e 15 de setembro às 21 horas da noite: Mata Ciliar $\left(18,4{ }^{\circ} \mathrm{C}\right)$, Cerrado $\left(17,9^{\circ} \mathrm{C}\right)$, Cerrado Arbóreo $\left(18,5^{\circ} \mathrm{C}\right)$ e Capão $\left(17,0^{\circ} \mathrm{C}\right)$.

A Mata Ciliar e o Cerrado Arbóreo, que têm média geral de temperatura do ar inferior ao do Cerrado, apresenta no dia 21 de setembro maior temperatura em relação ao mesmo. Levando em consideração os diversos fatores que envolvem cada ponto, sabe-se que a vegetação é de suma importância nesse caso, já que as árvores e vegetação rasteira - que estão presentes na Mata Ciliar e no Cerrado Arbóreo representam uma espécie de barreira à entrada de luz solar. Entretanto, a radiação solar que consegue infiltrar pelas camadas da vegetação, tem grande dificuldade de dissipação, resultando em maior temperatura à noite.

As cartas sinóticas e imagens de satélite dos dias 15/09/2016, 16/09/2016, 21/09/2016 e 22/09/2016 (figura 7) mostram a passagem de uma frente fria vinda do sul e que passa por toda região sul e sudeste do país. Os dados obtidos em campo mostram as maiores temperaturas registradas no dia 15/09/2016, fato que se explica pela aproximação da massa de ar frio $(\mathrm{mPa})$ o que causa o fenômeno conhecido como “aquecimento pré-frontal" vindo do sul e propiciando grande concentração de ar quente, uma vez que esse sistema pré-frontal apresenta baixa pressão e atrai os ventos das áreas de alta pressão vindos das regiões próximas à linha do Equador, resultando no aumento da temperatura na área de estudo, cuja média diária de temperatura foi de $27,1^{\circ} \mathrm{C}$.

Durante o intervalo dos dias 16/09/2016 a 21/09/2016 a massa atua sobre MG e as médias de temperatura variam de $22^{\circ} \mathrm{C}$ a $25^{\circ} \mathrm{C}$, já os valores de umidade relativa do ar vão dos $49 \%$ até $56 \%$. O dia 22/09/2016 
XVII Simpósio Brasileiro de Geografia Fisica Aplicada

I Congresso Nacional de Geografia Física
OS DESAFIOS DA GEOGRAFIA FÍSICA NA FRONTEIRA DO CONHECIMENTO

Instituto de Geociências - Unicamp

Campinas - SP

28 de Junho à 02 de Julho de 2017

foi o mais frio de toda a série, com médias de $19,6^{\circ} \mathrm{C}$ de temperatura e 55,87\% de umidade relativa do ar, devido ao fato da Massa Polar Atlântica $(\mathrm{mPa})$ ter passado por Minas Gerais e se encaminhado para o Oceano Atlântico, instalando-se nesse local uma área de alta pressão que resulta na descida do ar frio próximo a superfície. Em paralelo, outros sistemas atuam na América do Sul: na região norte do Brasil são formados centros de baixa pressão com grande formação de nuvens até o dia 16/09 e a diminuição das mesmas até o dia 22/09. O Anticiclone Subtropical do Pacífico Sul (ASPS) atua na parte oeste da América do Sul ocasionalmente ultrapassando os limites da cordilheira dos Andes. Na região sudoeste a Massa Polar Pacífica $(\mathrm{mPp})$ atua em diferentes intensidades durante o intervalo temporal analisado, com mais força durante os dias iniciais (15/09/2016 e 16/09/2016) e eventual redução nos dias 17/09/2016 e 18/09/2016, ganhando força nos dias posteriores. Na região leste, sobre o oceano Pacífico o ASPS atua de maneira mais localizada, não trazendo grandes efeitos sobre o país.

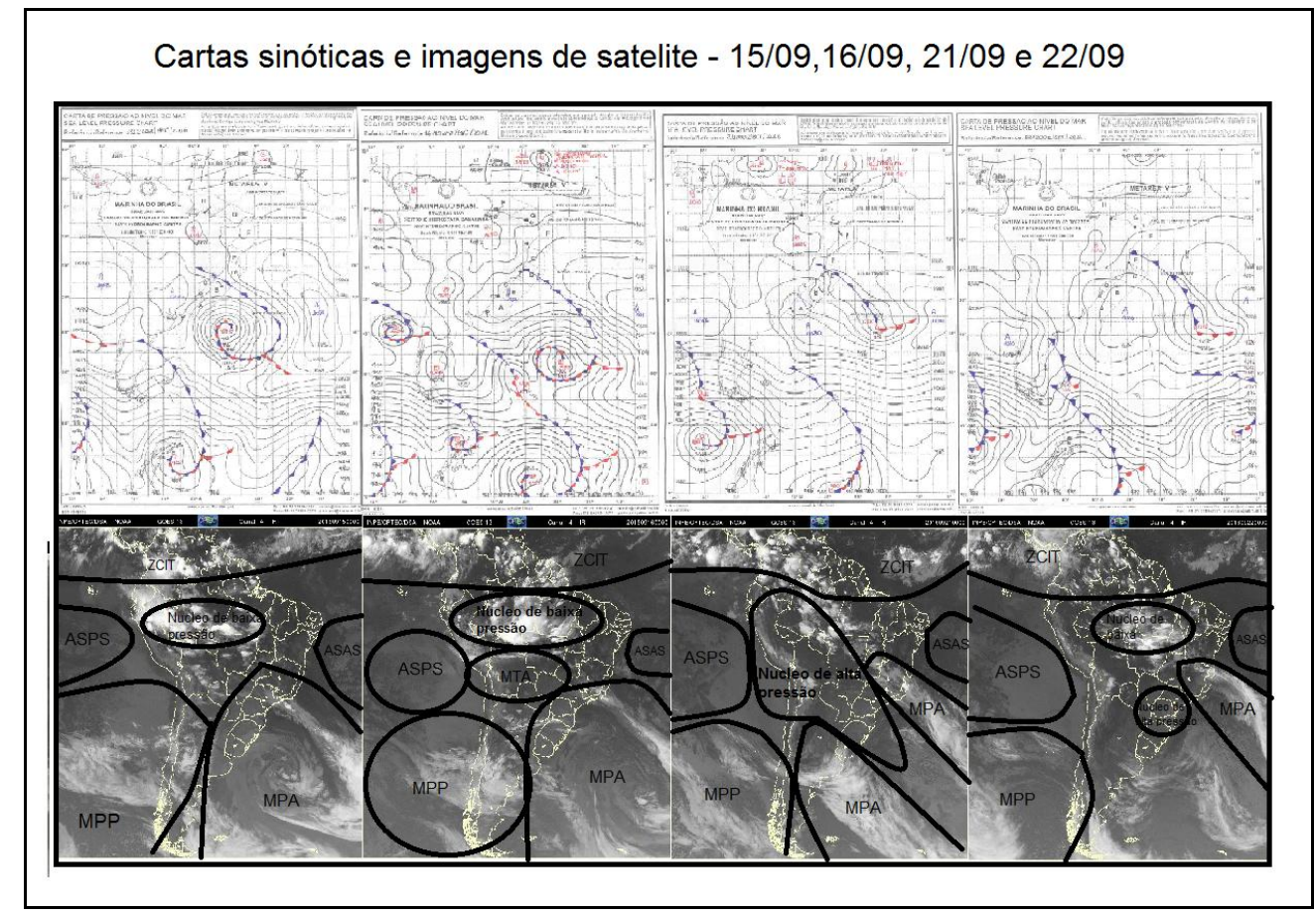

Figura 4- Sistemas atuantes nos dias 15, 16, 21 e 22 de setembro de 2016. Fonte: Elaborado pelos autores.

\section{Considerações Finais}

Com a análise completa dos dados, percebe-se que a umidade e a temperatura são extremamente influenciadas por fenômenos mesoclimáticos como as massas de ar. Durante os dias escolhidos para analisar, constatou-se direta interferência da ação de uma massa de ar frio nas temperaturas e umidade 
relativa do ar dos pontos estudados na Serra do Cipó. Entretanto, há uma variação dos elementos climáticos entre os pontos, que pode ser explicada pela influencia de fatores climáticos locais, como vegetação, altitude e relevo.

O fato de o Parque ser limítrofe a seis municípios e ter fácil acesso através da rodovia MG-010 ocasiona o livre transito de pessoas por todas as suas partes, pessoas que modificam elementos naturais da paisagem, mesmo que em uma microescala.

Os dados analisados mostram principalmente a variabilidade da temperatura, onde a vegetação é um fator de extrema influência para a conservação ou dissipação do calor e consequente conforto térmico do ambiente. Os dados referentes à temperatura podem ser usados no planejamento urbano, onde o conforto térmico é um importante ponto para melhorias na qualidade de vida.

\section{Bibliografia}

Centro de Hidrografia da Marinha Carta Sinótica. Disponível em: <https://www.mar.mil.br/dhn/chm/meteo/prev/cartas.htm>. Acesso em: 14/11/16.

GRIMM, A. M. Meteorologia. Extraído de: <http://fisica.ufpr.br/grimm/aposmeteo/> Data de acesso: set/2002.

IBGE - Instituto Brasileiro de Geografia e Estatística. Manual Técnico da Vegetação Brasileira. $2^{\mathrm{a} e d ~ r e v i s a d a ~ e ~}$ ampliada. 2012. $271 \mathrm{p}$.

MENDONÇA, F.; DANNI-OLIVEIRA, I. M. Climatologia: noções básicas e climas do Brasil. São Paulo: Oficina de Textos, 2007. $206 \mathrm{p}$.

MOLION, L.C.B.; 2005. Aquecimento global, El Niños, manchas solares, vulcões e Oscilação Decadal do Pacífico. Climanálise, n.8 (agosto), disponível em: 〈http://www6.cptec.inpe.br/revclima/revista〉.

MONTEIRO, C. A. F. Teoria e Cima Urbano. Tese (Livre Docência) - Faculdade de Filosofia, Letras e Ciências Humanas, Universidade de São Paulo, São Paulo, 1975.

MONTEIRO, C. A. F. O estudo geográfico do clima. Cadernos Geográficos, Florianópolis, n.1, 1999.

RIBEIRO, A. G. As escalas do clima. Boletim Geografia Teorética, Rio Claro, v. 23, p. 288-294, 1993

TORRES, F. T. P.; MACHADO, P. J. O. Introdução à Climatologia - Ubá: Ed. Geographica, 2008. - (Série de Textos Básicos de Geografia) 234 p. 